\title{
Correction to: Efficient removal of dyes from dyeing wastewater by powder activated charcoal/titanate nanotube nanocomposites: adsorption and photoregeneration
}

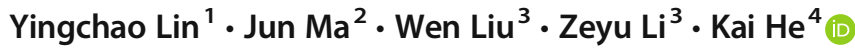

Published online: 11 March 2019

(C) Springer-Verlag GmbH Germany, part of Springer Nature 2019

\section{Correction to: Environmental Science and Pollution Research \\ https://doi.org/10.1007/s11356-019-04218-x}

The original publication of this paper contains a mistake.

The published Fig. 8 does not cite the related reference, and several grammar errors has been found in the image. The improved version of Fig. 8 and its caption is shown in this correction. These errors do not change the conclusions of this article.

The online version of the original article can be found at https://doi.org/ 10.1007/s11356-019-04218-x

Kai He

he.kai.7e@kyoto-u.ac.jp

1 College of Environmental Science and Engineering, Nankai University, Tianjin 300071, China

2 College of Environment and Safety, Taiyuan University of Science and Technology, Taiyuan 030024, China

3 College of Environmental Sciences and Engineering, Peking University, Beijing 100871, China

4 Research Centre for Environmental Quality Management, Kyoto University, 1-2 Yumihama, Otsu, Shiga, Japan 


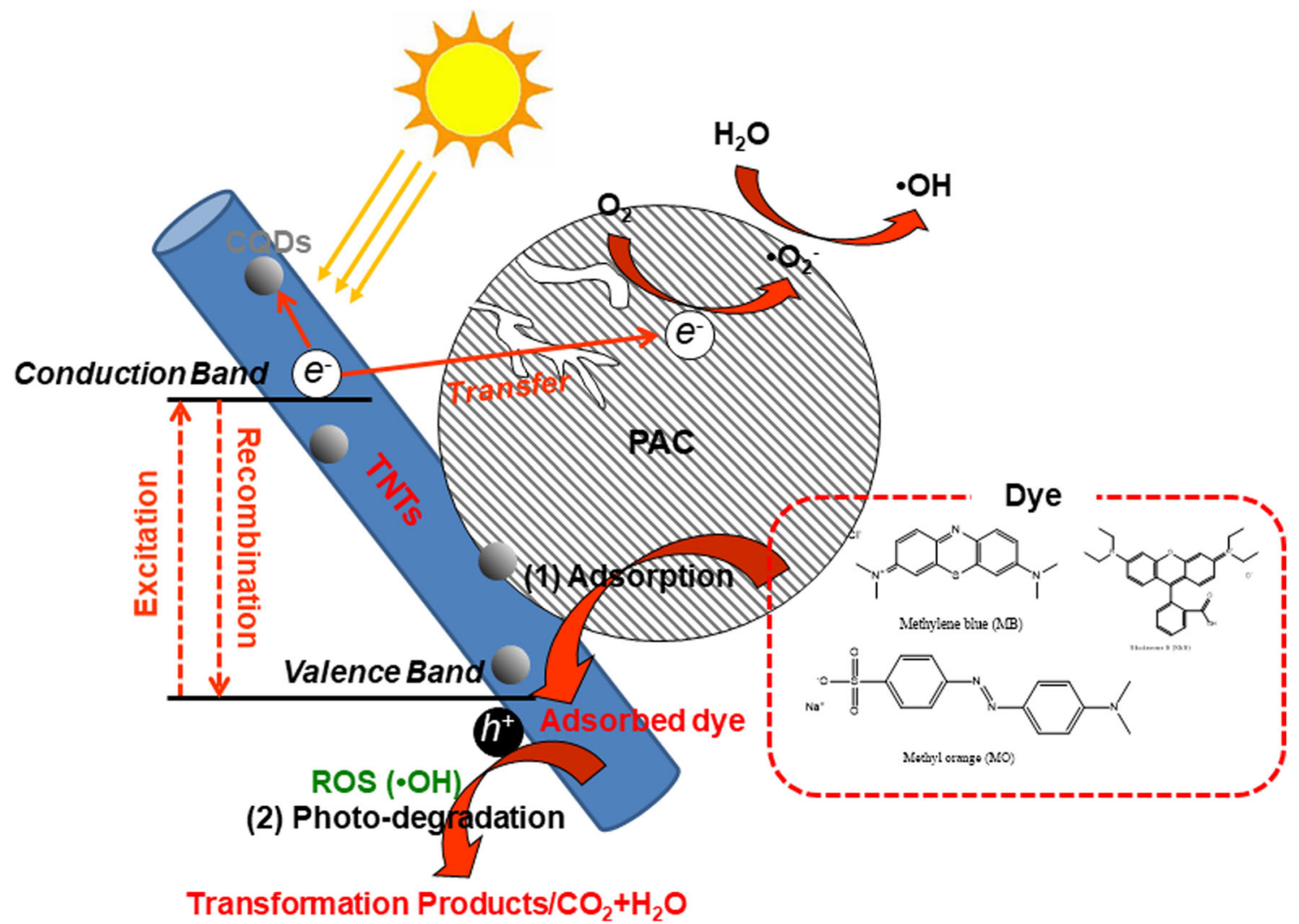

Fig. 8 Schematic of a two-step adsorption-photodegradation process for complete destruction of dyes by TNTs@ PAC (modified from Liu et al., 2016)

Publisher's note Springer Nature remains neutral with regard to jurisdictional claims in published maps and institutional affiliations. 